\title{
Prognostic value of electrocardiographic detection of unrecognized myocardial infarction in persons with stable coronary artery disease: data from the Heart and Soul Study
}

\author{
Devin W. Kehl · Ramin Farzaneh-Far • \\ Beeya Na - Mary A. Whooley
}

Received: 8 June 2010/Accepted: 3 November 2010/Published online: 20 November 2010

(C) The Author(s) 2010. This article is published with open access at Springerlink.com

\begin{abstract}
Unrecognized myocardial infarction (MI) carries a poor prognosis in the general population, but its prognostic value is less clear in high-risk patients. We sought to determine whether $\mathrm{Q}$ waves on electrocardiogram (ECG), suggestive of unrecognized MI, predict cardiovascular events in patients with stable coronary artery disease (CAD), but without a prior history of MI. We studied 462 patients enrolled in the Heart and Soul Study with stable CAD but without a prior history of MI. All patients had baseline ECGs. The baseline prevalence of unrecognized myocardial infarction was $36 \%$. After a mean of 6.3 years of follow-up, there were a total of 141 cardiovascular events. The presence of $\mathrm{Q}$ waves in any ECG lead territory predicted cardiovascular events before (unadjusted HR 1.41, 95\% CI 1.01-1.97) and after adjustment for demographics, medical history, diastolic function, and ejection fraction (HR 1.55, 95\% CI 1.06-2.26). This association was partly attenuated after adjustment for the presence of inducible ischemia at baseline (HR 1.43, 95\% CI 0.96-2.12). When specific
\end{abstract}

D. W. Kehl

Department of Medicine, University of California,

San Diego, San Diego, CA, USA

R. Farzaneh-Far $(\bowtie)$

Division of Cardiology, University of California,

San Francisco, Room 5G1, San Francisco General Hospital,

1001 Potrero Avenue, San Francisco, CA 94110, USA

e-mail: rfarzanehfar@medicine.ucsf.edu

B. Na $\cdot$ M. A. Whooley

Veterans Affairs Medical Center, San Francisco, CA, USA

M. A. Whooley

Department of Medicine, University of California,

San Francisco, San Francisco, CA, USA territories were analyzed separately, Q waves in anterior leads were predictive of cardiovascular events in both unadjusted and adjusted models (adjusted HR 1.85, 95\% CI 1.14-3.00), and this association was partly attenuated after adjustment for inducible ischemia. In conclusion, in patients with CAD but no history of prior MI, the presence of any Q waves or anterior Q waves alone is independently predictive of adverse cardiovascular events.

Keywords Q wave · Unrecognized myocardial infarction - Electrocardiogram - Coronary artery disease

\section{Introduction}

Unrecognized or "silent" myocardial infarction (MI) is common, and may account for $20-60 \%$ of all MI in otherwise asymptomatic patients over the age of 45 [1-4]. The diagnosis of unrecognized infarction has traditionally been defined as the presence of pathologic $\mathrm{Q}$ waves on the electrocardiogram (ECG) of a patient without a clinical history of MI. The prognostic significance of Q waves, indicative of unrecognized infarction, is similar to clinically recognized infarction in the general population [5]. Only one major study in asymptomatic subjects has suggested that unrecognized infarction may be more benign than recognized infarction [6]. Unrecognized infarcts are also at least as likely as recognized infarcts to lead to heart failure and stroke [7, 8]. Studies have further shown that Q waves carry an increased risk for impaired functional status and all-cause mortality, effects which both appear to be mediated by structural abnormalities suggestive of global rather than regional cardiac dysfunction [9].

The study of $\mathrm{Q}$ waves in unrecognized infarction has been conducted primarily in the general population. 
Limited studies of high-risk patients, or those with established coronary artery disease (CAD), have suggested that unrecognized infarction may be less common in women [10], but the prognostic value of electrocardiographic detection of unrecognized infarction in patients with CAD has not been well studied. In contrast to results from the general population, a significant association between unrecognized $\mathrm{Q}$ waves and adverse cardiac outcomes has not been observed in limited studies of patients with CAD [11], casting some doubt on the prognostic utility of electrocardiographic detection of infarction in this population. In light of these findings, we sought to determine the prognostic significance of $\mathrm{Q}$ waves on ECG in a large population of patients with stable CAD, absent a history of MI.

\section{Methods}

The Heart and Soul Study is a prospective cohort study investigating the effect of psychosocial factors on cardiovascular outcomes in patients with stable CAD. Details of the study methods have previously been described [12]. A total of 1,024 patients were enrolled between September 2000 and December 2002. Patients were recruited from outpatient clinics in the San Francisco Bay Area. All patients provided written informed consent and the study protocol was approved by the institutional review boards at all sites. Eligible participants met at least one of the following criteria: (1) history of MI, (2) angiographic evidence of at least $50 \%$ stenosis by area in at least one coronary artery, (3) evidence of exercise-induced ischemia by treadmill electrocardiogram or stress nuclear perfusion imaging, or (4) history of coronary revascularization. Individuals were excluded from this particular study if they had any history of MI, deemed themselves unable to walk 1 block, or if they were planning to move out of the local area within 3 years. Of the 1,024 patients initially enrolled in the Heart and Soul Study, 462 met these criteria and were included in the analysis.

All patients underwent baseline electrocardiography at enrollment. Q waves were determined manually by two independent and blinded internal medicine physicians. Using Minnesota Code Criteria [13] each physician classified Q waves as absent, possible (duration of 30-40 ms), or probable (duration $>40 \mathrm{~ms}$ ) in any lead of three lead territories: inferior (leads II, III, and aVF), lateral (leads I, aVL, V6), or anterior (leads V1-V5). Any discrepancies were resolved by consensus or (if necessary) by a third internal medicine physician. Possible and probable Q waves were pooled together for subsequent analysis.

All patients underwent complete resting two-dimensional echocardiography and Doppler examination using an
Acuson Sequoia ultrasound system (Siemens Medical Solutions, Mountain View, CA, USA) with a $3.5-\mathrm{MHz}$ transducer. Standard parasternal short-axis and apical two and four chamber views were obtained at rest and at peak exercise to detect the presence or development of left ventricular wall motion abnormalities. End-systolic and enddiastolic volumes were determined by planimetry. The left ventricular ejection fraction was calculated as (end diastolic volume-end systolic volume)/end diastolic volume. Diastolic dysfunction was defined as pseudonormal or restrictive based on the mitral Doppler inflow pattern [14]. Regional left ventricular function was assessed with a standard 16-segment model [15]. Segmental scores were assigned as follows: normal or hyperkinesis-1; hypokinesis-2; akinesis-3; dyskinesis-4; and aneurismal-5. The wall motion score index was derived as the sum of all scores divided by the number of segments visualized.

We assessed the presence of inducible cardiac ischemia using exercise treadmill testing with stress echocardiography [16]. We performed a symptom-limited, graded exercise treadmill test according to a standard Bruce protocol. Inducible ischemia was defined as the presence of new wall motion abnormalities at peak exercise that were not present at rest. The results from stress echocardiography were interpreted by a single expert cardiologist, who was blinded to the presence of self-reported angina.

Age, sex, ethnicity, smoking status, and medical history were determined by self-report. Systolic and diastolic blood pressures $(\mathrm{mm} \mathrm{Hg})$ were measured with the patient at rest by trained study personnel using a calibrated sphygmomanometer. Weight and height were measured to calculate body mass index $\left(\mathrm{kg} / \mathrm{m}^{2}\right)$. Participants were instructed to bring their medication bottles to the study appointment, and study personnel recorded all current medications using Epocrates Rx (San Mateo, CA, USA).

We conducted annual telephone interviews with participants or their proxies regarding recent emergency room visits, hospitalizations, or death. Medical treatment at follow-up was not recorded. For any reported event, medical records, death certificates, and coroner's reports were reviewed by two independent and blinded adjudicators. If the adjudicators agreed on the outcome classification, their classification was binding. If they disagreed, a third blinded adjudicator reviewed the event and determined the outcome classification.

The primary outcome was cardiovascular events, a composite of all-cause death, nonfatal MI, and stroke. Nonfatal MI was defined by the American Heart Association diagnostic criteria [17]. Stroke was defined as a new neurological deficit not known to be secondary to brain trauma, tumor, infection, or other cause [18]. Other outcomes ascertained included hospitalization for heart failure, which was defined as a minimum one-night hospital 
stay for a clinical syndrome comprising at least two of the following: paroxysmal nocturnal dyspnea, orthopnea, elevated jugular venous pressure, pulmonary rales, third heart sound, and cardiomegaly or pulmonary edema on chest radiography [19]. These clinical signs and symptoms must have represented a clear change from the baseline clinical status of the participant and must have been accompanied by either failing cardiac output as determined by peripheral hypoperfusion (in the absence of other causes such as sepsis or dehydration) or peripheral or pulmonary edema requiring intravenous diuretics, inotropes, or vasodilators. All-cause mortality was determined by review of death certificates.

Differences in baseline characteristics were compared with the use of analysis of variance for continuous variables and the chi-squared test for dichotomous variables, as appropriate. Using the Kaplan-Meier technique, the probability of survival free from cardiovascular events was plotted against time for the presence of any $\mathrm{Q}$ waves and anterior $\mathrm{Q}$ waves. Cox proportional hazards models were used to examine the association between $\mathrm{Q}$ waves in any ECG territory and cardiovascular events. Cox models were also used to separately evaluate the association of Q waves in each of the three ECG territories with cardiovascular events. Multivariate adjustment was performed sequentially for age, gender, ethnicity, past history of smoking, history of congestive heart failure, and diastolic dysfunction, followed by either left ventricular ejection fraction or resting wall motion score and inducible ischemia. These covariates for the multivariable models were chosen a priori based on published associations and biologic plausibility. Covariate selection was checked by visual inspection of directed acyclic graphs [20]. From the Cox models, unadjusted and adjusted hazard ratios (HR) with 95\% confidence intervals (CI) were obtained. Participants were censored at date of first event or last contact, whichever came first. Outcome ascertainment was complete in $99 \%$ of participants. Statistical analysis was performed using SAS software version 9.1 (SAS Institute Inc).

\section{Results}

In 462 participants without a history of prior MI, 199 Q waves were identified on baseline ECG in 167 participants (36\%). When accounting for the 562 patients excluded from the study for a history of recognized infarction, unrecognized infarction accounted for $23 \%$ of all infarctions and was present in $16 \%$ of all patients enrolled in the Heart and Soul Study. The regional distribution of the Q waves was as follows: anterior $136(68 \%)$, inferior $9(5 \%)$, and lateral 54(27\%).
Compared with participants without $\mathrm{Q}$ waves, those with $\mathrm{Q}$ waves in any territory were less likely to have a history of prior smoking, and somewhat more likely to have a history of heart failure (Table 1). There were no significant differences between participants with $\mathrm{Q}$ waves compared with those without $\mathrm{Q}$ waves with respect to age, gender, ethnicity, other medical history, medications, or echocardiographic measures including left ventricular ejection fraction, diastolic dysfunction, resting wall motion score, and inducible ischemia.

During a mean follow-up of 6.3 years, there were 141 non-overlapping cardiovascular events (116 deaths, 14 strokes, 43 nonfatal MIs) (Table 2). The annual event rate was $4.5 \%$ among patients without $\mathrm{Q}$ waves, compared with $6.2 \%$ among patients with any $\mathrm{Q}$ waves $(p=0.05)$ (Table 2). No significant differences were found between patients with and without any $\mathrm{Q}$ waves with respect to event rates for all-cause death, nonfatal MI, or stroke alone (Table 2). Figure 1 demonstrates the survival curve for freedom from cardiovascular events for the presence of any $\mathrm{Q}$ waves compared with the absence of $\mathrm{Q}$ waves.

In the unadjusted Cox model, the presence of $\mathrm{Q}$ waves in any territory was associated with a $41 \%$ increase in risk for adverse cardiovascular events (HR 1.41, $p=0.05$; 95\% CI 1.01-1.97) (Table 3). This association remained after sequential adjustment for age (Model 1), gender, ethnicity, and history of prior smoking (Model 2), history of heart failure and diastolic dysfunction (Model 3), and left ventricular ejection fraction (Model 4 adjusted HR 1.55, $p=0.02$, 95\% CI 1.06-2.26) (Table 3). When ejection fraction was replaced by resting wall motion score in the adjustment model, the association remained significant (Model 5 adjusted HR 1.59, $p=0.02,95 \%$ CI 1.09-2.30) (Table 3), but it was partly attenuated after subsequent adjustment for inducible ischemia (Model 6 adjusted HR $1.43, p=0.08,95 \%$ CI 0.96-2.12) (Table 3). The presence of $\mathrm{Q}$ waves in any territory was not associated with increased risk for all-cause death in unadjusted (HR 1.37, $p=0.10,95 \%$ CI $0.95-1.96$ ) or adjusted models (Model 4 adjusted HR 1.38, $p=0.14,95 \%$ CI $0.90-2.10$ ). A nonsignificant trend toward an association was found in adjustment model 5 (Model 5 adjusted HR 1.47, $p=0.07$, 95\% CI 0.97-2.23), which was not present after subsequent adjustment for inducible ischemia (Model 6 adjusted HR $1.34, p=0.20,95 \%$ CI 0.86-2.08).

In Cox models analyzing the prognostic relevance of $\mathrm{Q}$ wave territory, participants with lateral $\mathrm{Q}$ waves did not show increased risk for cardiovascular events compared with those without any Q waves (unadjusted HR 1.19, 95\% CI 0.84-1.70; Model 6 adjusted HR 1.21, 95\% CI 0.79-1.86) (Table 4). Participants with inferior $\mathrm{Q}$ waves showed trends toward increased risk for cardiovascular events compared with those without any Q waves, but these 
Table 1 Baseline characteristics of study population categorized by presence or absence of $\mathrm{Q}$ waves

Data reported as $N(\%)$ or mean \pm standard deviation

\begin{tabular}{llll}
\hline Variable & $\begin{array}{l}\text { No Q waves } \\
(N=295)\end{array}$ & $\begin{array}{l}\text { Any Q wave } \\
(N=167)\end{array}$ & $P$ value \\
\hline Age (years) & $67 \pm 11$ & $67 \pm 10$ & 0.53 \\
Male & $240(81)$ & $127(76)$ & 0.18 \\
White & $175(59)$ & $88(53)$ & 0.17 \\
Body mass index $\left(\mathrm{kg} / \mathrm{m}^{2}\right)$ & $28.8 \pm 5.2$ & $28.5 \pm 5.5$ & 0.59 \\
Current smoking & $48(16)$ & $35(21)$ & 0.20 \\
Prior smoking & $144(50)$ & $66(40)$ & 0.05 \\
Hypertension & $206(70)$ & $119(72)$ & 0.67 \\
History of congestive heart failure & $28(9)$ & $25(15)$ & 0.07 \\
History of stroke & $28(9)$ & $19(11)$ & 0.52 \\
History of diabetes & $77(26)$ & $38(23)$ & 0.42 \\
Revascularization & $148(50)$ & $82(49)$ & 0.87 \\
Statin use & $182(62)$ & $93(56)$ & 0.21 \\
Aspirin use & $221(75)$ & $117(70)$ & 0.26 \\
Beta-blocker use & $153(52)$ & $84(50)$ & 0.75 \\
Renin-angiotensin inhibitor use & $128(43)$ & $79(47)$ & $135.9 \pm 21.4$ \\
Systolic blood pressure $(\mathrm{mmHg})$ & $133.7 \pm 19.4$ & $76.4 \pm 11.8$ & 0.42 \\
Diastolic blood pressure $(\mathrm{mmHg})$ & $75.0 \pm 11.4$ & $63.9 \pm 8.2$ & 0.27 \\
Left ventricular ejection fraction & $63.8 \pm 7.1$ & $96.8 \pm 28.8$ & 0.21 \\
Left ventricular mass index $\left(\mathrm{g} / \mathrm{m}^{2}\right)$ & $94.3 \pm 24.7$ & $18(13)$ & 0.95 \\
Diastolic dysfunction & $25(10)$ & $29(19)$ & 0.32 \\
Inducible ischemia & $47(17)$ & $1.07 \pm 0.21$ & 0.35 \\
Resting wall motion score & $1.06 \pm 0.21$ & & 0.65 \\
\hline & & & 0.62 \\
\hline
\end{tabular}

Table 2 Adverse cardiovascular outcomes categorized by presence or absence of Q waves

\begin{tabular}{|c|c|c|c|c|c|}
\hline \multirow[t]{2}{*}{ OUTCOME } & \multicolumn{2}{|c|}{ No Q waves $(N=295)$} & \multicolumn{2}{|c|}{ Any Q wave $(N=167)$} & \multirow{2}{*}{$\begin{array}{l}P \text { value for } \\
\text { annual event rate }\end{array}$} \\
\hline & Total events & Annual rate & Total events & Annual rate & \\
\hline $\begin{array}{l}\text { Cardiovascular events (all-cause death, } \\
\text { nonfatal myocardial infarction, or stroke) }\end{array}$ & 82 & 0.045 & 59 & 0.062 & 0.05 \\
\hline All-cause death & 68 & 0.035 & 48 & 0.047 & 0.17 \\
\hline Nonfatal myocardial infarction & 26 & 0.014 & 17 & 0.017 & 0.56 \\
\hline Stroke & 7 & 0.004 & 7 & 0.007 & 0.25 \\
\hline Congestive heart failure hospitalization & 33 & 0.018 & 27 & 0.028 & 0.11 \\
\hline
\end{tabular}

did not reach statistical significance and the confidence intervals were wide with only nine inferior $\mathrm{Q}$ waves noted among participants (Model 6 adjusted HR 2.53, 95\% CI 0.70-9.03) (Table 4). Participants with anterior Q waves showed a statistically significant, $80 \%$ increased risk for cardiovascular events compared with those without any $\mathrm{Q}$ waves in the unadjusted model as well as the first four sequential adjustment models (unadjusted HR 1.80, 95\% CI 1.15-2.82; Model 4 adjusted HR 1.85, 95\% CI 1.14-3.00) (Table 4). This association was maintained when resting wall motion score was substituted for ejection fraction in the adjustment model (Model 5 adjusted HR 1.80, 95\% CI 1.11-2.93), and attenuated modestly after further adjustment for inducible ischemia (Model 6 adjusted HR 1.61, 95\% CI 0.95-2.78) (Table 4). Figure 2 demonstrates the survival curve for freedom from cardiovascular events for the presence of anterior $Q$ waves compared with the absence of any $\mathrm{Q}$ waves.

\section{Discussion}

In patients with stable CAD but without prior history of $\mathrm{MI}$, we found that the presence of any $\mathrm{Q}$ wave on baseline ECG is independently associated with adverse cardiovascular events including death, nonfatal MI, and stroke. This association does not appear to be mediated by global echocardiographic parameters of systolic or diastolic 
Fig. 1 Kaplan-Meier survival curves showing freedom from cardiovascular events $(p=0.05$ from log rank test)

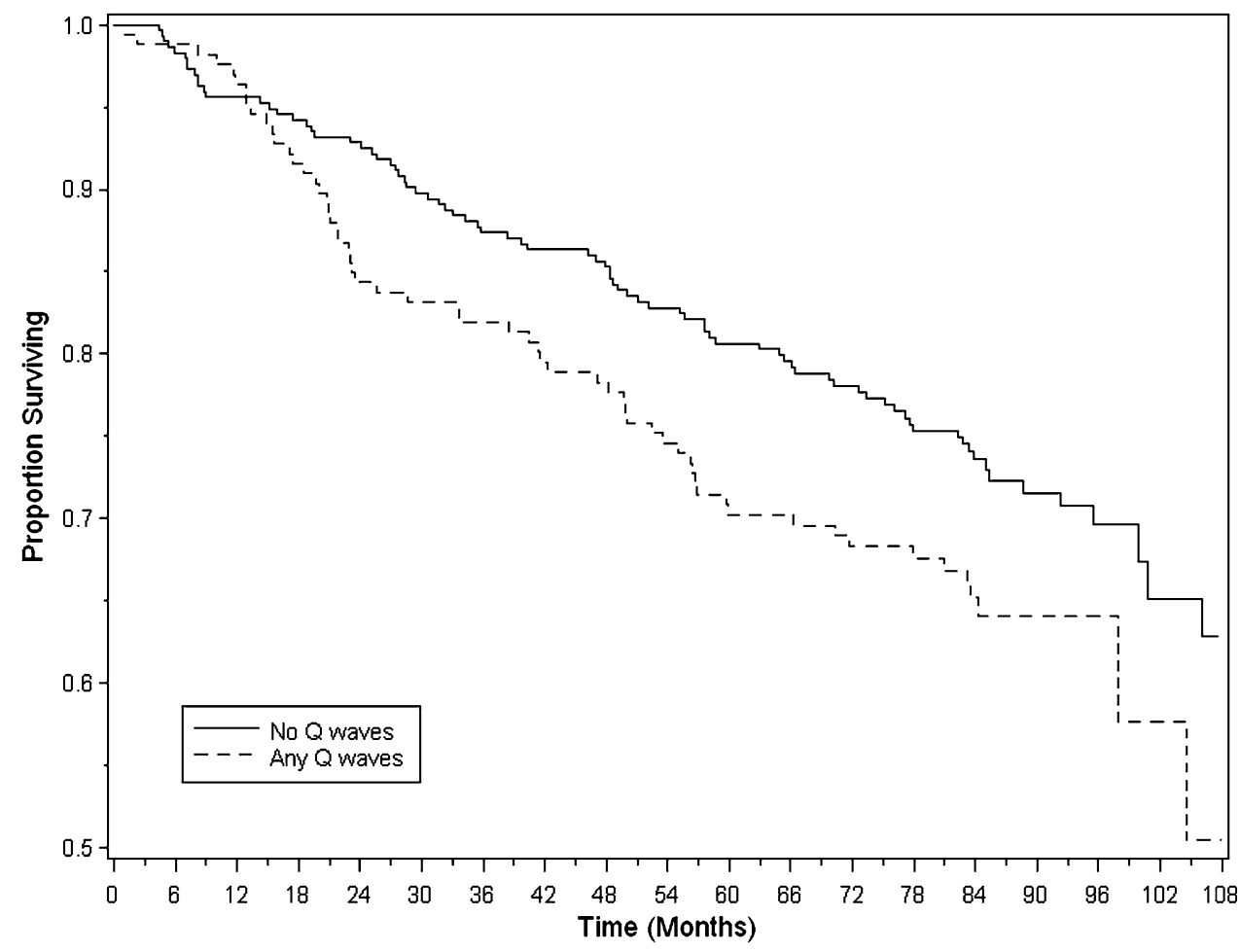

Table 3 Association of Q waves in any territory with cardiovascular events (all-cause death, nonfatal myocardial infarction, stroke)

\begin{tabular}{lll}
\hline Model & Any Q wave HR $(95 \% \mathrm{CI})$ & $P$ value \\
\hline Unadjusted & $1.41(1.01-1.97)$ & 0.05 \\
${\text { Model } 1^{\mathrm{a}}}^{\mathrm{a}}$ & $1.39(0.99-1.94)$ & 0.06 \\
Model $2^{\mathrm{b}}$ & $1.44(1.03-2.03)$ & 0.04 \\
Model $3^{\mathrm{c}}$ & $1.50(1.04-2.17)$ & 0.03 \\
Model $4^{\mathrm{d}}$ & $1.55(1.06-2.26)$ & 0.02 \\
Model $5^{\mathrm{e}}$ & $1.59(1.09-2.30)$ & 0.02 \\
Model $^{\mathrm{f}}$ & $1.43(0.96-2.12)$ & 0.08 \\
\hline
\end{tabular}

${ }^{\text {a }}$ Model $1=$ Age

b Model $2=$ Model $1+$ gender, ethnicity, prior smoking

c Model 3 = Model $2+$ history of congestive heart failure, diastolic dysfunction

${ }^{\mathrm{d}}$ Model $4=$ Model $3+$ left ventricular ejection fraction

e Model $5=$ Model $3+$ wall motion score

${ }^{\mathrm{f}}$ Model $6=$ Model $5+$ inducible ischemia

function, but may be mediated in part by inducible cardiac dysfunction. Our findings extend the current literature on unrecognized infarction to a high-risk population in which this entity has been less well characterized. The results contrast with observations from prior small studies in this population, but are in concordance with larger studies in the general population. We demonstrate that unrecognized MI is both highly prevalent and prognostically important, even in a high-risk population under close medical surveillance. Furthermore, Q waves in anterior territories alone were associated with increased risk.

The prevalence of unrecognized Q-wave infarction in this study among patients with CAD but without known infarction is notably higher (36\%) than reported previously in similar populations $(8-12 \%)[11,21]$. The proportion of unrecognized Q-wave MI in our study population was $23 \%$ of all MI, which was also notably higher than a previously reported proportion of $4.3 \%$ in a population of women with CAD [10]. Although estimates of the reported rates of unrecognized infarction can vary significantly depending on electrocardiographic criteria used for diagnosis [3], our detection methodology was similar to prior studies in this population. A more likely explanation for the discrepancy in prevalence is a greater disease burden in our population of predominantly male patients. Alternatively, our population may have had a higher proportion of Q-wave compared with non-Q-wave MI. Recent studies have shown that total infarct size and endocardial extent of infarction correlate best with Q waves on ECG [22, 23], a finding which is consistent with the physiologic basis of $\mathrm{Q}$ waves as a reflection of the absence of depolarizing currents within the endocardium [24]. The population in this study could have suffered larger infarcts involving more endocardium, thereby demonstrating a higher fraction of Qwave compared with non-Q-wave infarctions.

One prior study in the general population suggested that in patients with impaired functional status, global myocardial dysfunction may mediate an association between 
Table 4 Association of Q waves in specific territories with cardiovascular events (all-cause death, nonfatal myocardial infarction, stroke)

\begin{tabular}{|c|c|c|c|}
\hline Model & Lateral Q waves HR $(95 \% \mathrm{CI})$ & Inferior Q waves HR $(95 \% \mathrm{CI})$ & Anterior Q waves $\mathrm{HR}(95 \% \mathrm{CI})$ \\
\hline Unadjusted & $1.19(0.84-1.70)$ & $1.80(0.66-4.86)$ & $1.80(1.15-2.82)$ \\
\hline Model $1^{\mathrm{a}}$ & $1.21(0.85-1.72)$ & $1.80(0.66-4.85)$ & $1.75(1.12-2.75)$ \\
\hline Model $2^{\mathrm{b}}$ & $1.24(0.87-1.78)$ & $2.10(0.77-5.77)$ & $1.88(1.19-2.96)$ \\
\hline Model $3^{c}$ & $1.25(0.84-1.86)$ & $2.27(0.82-6.31)$ & $1.79(1.10-2.91)$ \\
\hline Model $4^{\mathrm{d}}$ & $1.24(0.83-1.86)$ & $2.18(0.79-6.07)$ & $1.85(1.14-3.00)$ \\
\hline Model $5^{\mathrm{e}}$ & $1.32(0.89-1.96)$ & $2.11(0.75-5.94)$ & $1.80(1.11-2.93)$ \\
\hline Model $6^{\mathrm{f}}$ & $1.21(0.79-1.86)$ & $2.52(0.70-9.03)$ & $1.61(0.94-2.78)$ \\
\hline
\end{tabular}

${ }^{a}$ Model 1 = Age

${ }^{\mathrm{b}}$ Model $2=$ Model $1+$ gender, ethnicity, prior smoking

c Model 3 = Model $2+$ history of congestive heart failure, diastolic dysfunction

${ }^{\mathrm{d}}$ Model $4=$ Model $3+$ left ventricular ejection fraction

${ }^{\mathrm{e}}$ Model $5=$ Model $3+$ wall motion score

${ }^{\mathrm{f}}$ Model $6=$ Model $5+$ inducible ischemia

Fig. 2 Kaplan-Meier survival curves showing freedom from cardiovascular events ( $p=0.006$ from log rank test)

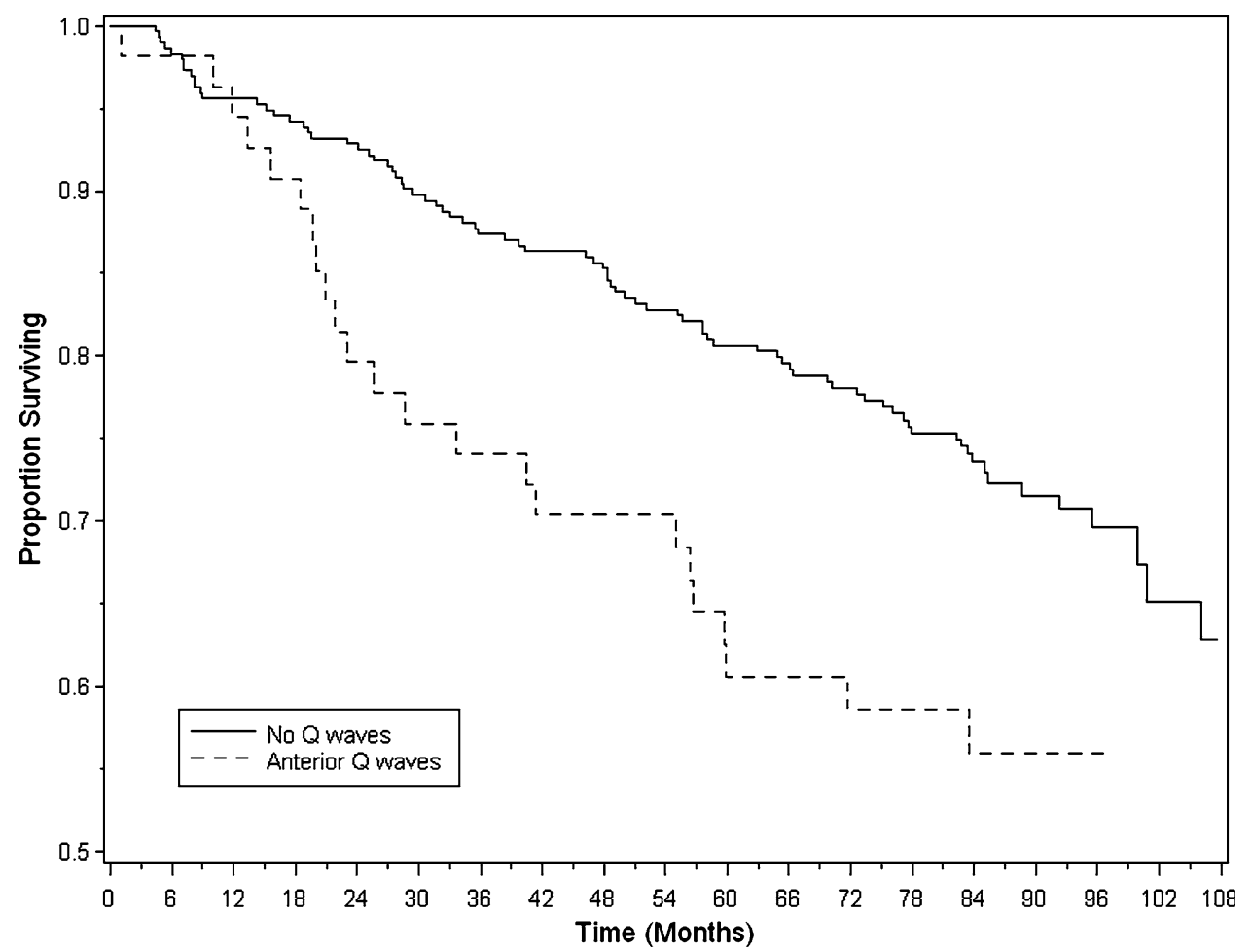

unrecognized Q waves and mortality, even in the absence of regional wall motion abnormalities [9]. In contrast, in our study adjustment for left ventricular ejection fraction and diastolic dysfunction did not attenuate the association between $\mathrm{Q}$ waves and adverse cardiovascular events. This is consistent with a biological mechanism distinct from global myocardial dysfunction. Adjustment for exerciseinduced, though not resting, segmental wall motion abnormalities did attenuate the association modestly, suggesting that the prognostic importance of this ECG marker may act in part through segmental, but not global, dysfunction in patients with CAD.
Our finding that $\mathrm{Q}$ waves in anterior lead territories predict poor outcomes but not those in inferior or lateral territories is to our knowledge the first demonstration of the prognostic importance of $\mathrm{Q}$ wave location in unrecognized infarction. This result is consistent with cardiac magnetic resonance imaging (MRI) data which have shown a strong correlation between infarct size and $\mathrm{Q}$ wave presence only in anterior territories, and not in lateral or inferior territories [25]. Therefore, this finding could be due to a greater specificity of $\mathrm{Q}$ waves for myocardial scar in anterior territories. Alternatively, this result could indicate a greater clinical impact of segmental wall dysfunction due to scar in 
the anterior myocardial wall compared with the inferior or lateral walls. Importantly, we cannot exclude an association of inferior territories with adverse outcomes, as the magnitudes of this association reported in Table 4 were in fact greater for inferior territories than anterior territories. However, the small number of inferior $\mathrm{Q}$ waves noted in the study population contributed to very wide confidence intervals and precludes a reliable conclusion about the differential impact of $\mathrm{Q}$ waves across territories.

The strengths of the current study include a large sample size, virtually complete outcome ascertainment, and adjustment for multiple variables including baseline characteristics and echocardiographic parameters. However, there are several important limitations that should also be considered in the evaluation of our findings. First, although the total sample was sizeable, the sample sizes for analysis of each $\mathrm{Q}$ wave territory were much smaller, particularly for inferior and lateral territories. Second, the high proportion of male participants in the study population limits generalizability to women. Third, patients with $\mathrm{Q}$ waves in multiple territories were not analyzed separately. Some data suggest that patients with lateral $Q$ waves in addition to anterior $\mathrm{Q}$ waves may be at greater risk for left ventricular thrombus formation than those with anterior $Q$ waves alone [26]. Fourth, survival bias inherent in the study of unrecognized infarction may have weakened the associations we report. Finally, we did not perform cardiac MRI to determine the presence of non-Q-wave unrecognized MI or confirm the presence of myocardial scar in patients with Q waves. Unrecognized Q-wave infarction may account for only a fraction of all clinically significant unrecognized MI [21], and estimates of the specificity of Q waves for infarction have ranged from 20 to $100 \%[11,21$, 22]. Nevertheless, the importance of this study is that even without the use of more advanced technologies, important prognostic information can be obtained from a simple ECG.

In conclusion, in a cohort of patients with stable CAD but without prior history of MI, we demonstrated that the prevalence of unrecognized infarction is comparable to the prevalence in the general population. We further observed that the detection of $\mathrm{Q}$ waves, in any lead or anterior leads alone, on routine ECG predicts adverse cardiovascular outcomes independently of established risk factors, medical history, and echocardiographic parameters of global systolic and diastolic function. Finally, this association may act in part through inducible segmental wall dysfunction.

Acknowledgments The Heart and Soul Study was funded by the Department of Veterans Affairs, Washington DC, the National Heart Lung and Blood Institute (RO1 HL079235), Bethesda, MD, the American Federation for Aging Research (Paul Beeson Scholars Program), New York NY, the Robert Wood Johnson Foundation
(Faculty Scholars Program), Princeton NJ, and the Nancy Kirwan Heart Research Fund, San Francisco CA.

Open Access This article is distributed under the terms of the Creative Commons Attribution Noncommercial License which permits any noncommercial use, distribution, and reproduction in any medium, provided the original author(s) and source are credited.

\section{References}

1. de Torbal A, Boersma E, Kors JA, van Herpen G, Deckers JW, van der Kuip DA, Stricker BH, Hofman A, Witteman JC (2006) Incidence of recognized and unrecognized myocardial infarction in men and women aged 55 and older: the Rotterdam Study. Eur Heart J 27:729-736

2. Sheifer SE, Manolio TA, Gersh BJ (2001) Unrecognized myocardial infarction. Ann Intern Med 135:801-811

3. Ammar KA, Yawn BP, Urban L, Mahoney DW, Kors JA, Jacobsen S, Rodeheffer RJ (2005) Identification of optimal electrocardiographic criteria for the diagnosis of unrecognized myocardial infarction: a population-based study. Ann Noninvasive Electrocardiol 10:197-205

4. Boland LL, Folsom AR, Sorlie PD, Taylor HA, Rosamond WD, Chambless LE, Cooper LS (2002) Occurrence of unrecognized myocardial infarction in subjects aged 45 to 65 years (the ARIC study). Am J Cardiol 90:927-931

5. Sigurdsson E, Thorgeirsson G, Sigvaldason H, Sigfusson N (1995) Unrecognized myocardial infarction: epidemiology, clinical characteristics, and the prognostic role of angina pectoris. The Reykjavik Study. Ann Intern Med 122:96-102

6. Medalie JH, Goldbourt U (1976) Unrecognized myocardial infarction: five-year incidence, mortality, and risk factors. Ann Intern Med 84:526-531

7. Kannel WB, Abbott RD (1984) Incidence and prognosis of unrecognized myocardial infarction. An update on the Framingham study. N Engl J Med 311:1144-1147

8. Ikram MA, Hollander M, Bos MJ, Kors JA, Koudstaal PJ, Hofman A, Witteman JC, Breteler MM (2006) Unrecognized myocardial infarction and the risk of stroke: the Rotterdam Study. Neurology 67:1635-1639

9. Ammar KA, Makwana R, Jacobsen SJ, Kors JA, Burnett JC Jr, Redfield MM, Yawn BP, Rodeheffer RJ (2007) Impaired functional status and echocardiographic abnormalities signifying global dysfunction enhance the prognostic significance of previously unrecognized myocardial infarction detected by electrocardiography. Ann Noninvasive Electrocardiol 12:27-37

10. Shlipak MG, Elmouchi DA, Herrington DM, Lin F, Grady D, Hlatky MA (2001) The incidence of unrecognized myocardial infarction in women with coronary heart disease. Ann Intern Med 134:1043-1047

11. Kwong RY, Chan AK, Brown KA, Chan CW, Reynolds HG, Tsang S, Davis RB (2006) Impact of unrecognized myocardial scar detected by cardiac magnetic resonance imaging on eventfree survival in patients presenting with signs or symptoms of coronary artery disease. Circulation 113:2733-2743

12. Ruo B, Rumsfeld JS, Hlatky MA, Liu H, Browner WS, Whooley MA (2003) Depressive symptoms and health-related quality of life: the Heart and Soul Study. JAMA 290:215-221

13. Blackburn H, Keys A, Simonson E, Rautaharju P, Punsar S (1960) The electrocardiogram in population studies. A classification system. Circulation 21:1160-1175

14. Ren X, Ristow B, Na B, Ali S, Schiller NB, Whooley MA (2007) Prevalence and prognosis of asymptomatic left ventricular 
diastolic dysfunction in ambulatory patients with coronary heart disease. Am J Cardiol 99:1643-1647

15. Lang RM, Bierig M, Devereux RB, Flachskampf FA, Foster E, Pellikka PA, Picard MH, Roman MJ, Seward J, Shanewise JS, Solomon SD, Spencer KT, Sutton MS, Stewart WJ (2005) Recommendations for chamber quantification: a report from the American Society of Echocardiography's Guidelines and Standards Committee and the Chamber Quantification Writing Group, developed in conjunction with the European Association of Echocardiography, a branch of the European Society of Cardiology. J Am Soc Echocardiogr 18:1440-1463

16. Lee TH, Boucher CA (2001) Clinical practice. Noninvasive tests in patients with stable coronary artery disease. N Engl J Med 344:1840-1845

17. Luepker RV, Apple FS, Christenson RH, Crow RS, Fortmann SP, Goff D, Goldberg RJ, Hand MM, Jaffe AS, Julian DG, Levy D, Manolio T, Mendis S, Mensah G, Pajak A, Prineas RJ, Reddy KS, Roger VL, Rosamond WD, Shahar E, Sharrett AR, Sorlie P, Tunstall-Pedoe H (2003) Case definitions for acute coronary heart disease in epidemiology and clinical research studies: a statement from the AHA Council on Epidemiology and Prevention; AHA Statistics Committee; World Heart Federation Council on Epidemiology and Prevention; the European Society of Cardiology Working Group on Epidemiology and Prevention; Centers for Disease Control and Prevention; and the National Heart, Lung, and Blood Institute. Circulation 108:2543-2549

18. Angeja BG, Shlipak MG, Go AS, Johnston SC, Frederick PD, Canto JG, Barron HV, Grady D (2001) Hormone therapy and the risk of stroke after acute myocardial infarction in postmenopausal women. J Am Coll Cardiol 38:1297-1301
19. Redfield MM, Jacobsen SJ, Burnett JC Jr, Mahoney DW, Bailey KR, Rodeheffer RJ (2003) Burden of systolic and diastolic ventricular dysfunction in the community: appreciating the scope of the heart failure epidemic. JAMA 289:194-202

20. Shrier I, Platt RW (2008) Reducing bias through directed acyclic graphs. BMC Med Res Methodol 8:70

21. Kim HW, Klem I, Shah DJ, Wu E, Meyers SN, Parker MA, Crowley AL, Bonow RO, Judd RM, Kim RJ (2009) Unrecognized non-Q-wave myocardial infarction: prevalence and prognostic significance in patients with suspected coronary disease. PLoS Med 6:e1000057

22. Engblom H, Carlsson MB, Hedstrom E, Heiberg E, Ugander M, Wagner GS, Arheden H (2007) The endocardial extent of reperfused first-time myocardial infarction is more predictive of pathologic Q waves than is infarct transmurality: a magnetic resonance imaging study. Clin Physiol Funct Imaging 27:101-108

23. Kaandorp TA, Bax JJ, Lamb HJ, Viergever EP, Boersma E, Poldermans D, van der Wall EE, de Roos A (2005) Which parameters on magnetic resonance imaging determine $\mathrm{Q}$ waves on the electrocardiogram? Am J Cardiol 95:925-929

24. Michael MA, El Masry H, Khan BR, Das MK (2007) Electrocardiographic signs of remote myocardial infarction. Prog Cardiovasc Dis 50:198-208

25. Rovai D, Di Bella G, Rossi G, Lombardi M, Aquaro GD, L'Abbate A, Pingitore A (2007) Q-wave prediction of myocardial infarct location, size and transmural extent at magnetic resonance imaging. Coron Artery Dis 18:381-389

26. Lamas GA, Vaughan DE, Pfeffer MA (1990) Significance of a lateral $\mathrm{Q}$ wave following first anterior wall acute myocardial infarction. Am J Cardiol 65:674-675 